\section{Fundamental models of structural stability}

The Mining-Geology-Petroleum Engineering Bulletin UDC: 621:622

DOI: $10.17794 / \operatorname{rgn} .2017 \cdot 2.5$

Review scientific paper

\author{
Antonia Jaguljnjak Lazarević́; ; Mario Uroš; ${ }^{2}$ Ana Čengija ${ }^{3}$ \\ ${ }^{1}$ Faculty of Mining, Geology and Petroleum Engineering, University of Zagreb, Pierottijeva 6, HR-10000 Zagreb, Croatia \\ ${ }^{2}$ Faculty of Civil Engineering, University of Zagreb, Fra Andrije Kačića-Miošića 26, HR-10000 Zagreb, Croatia \\ ${ }^{3} 2$ Struge 22, HR-10000 Zagreb, Croatia
}

\begin{abstract}
In this paper, basic structural stability phenomena are described. After some general comments about stability in the field of civil engineering, four elementary sources of nonlinearity are mentioned: of equilibrium equations, strain (geometry) relations, material (stress-strain) law, force and displacement boundary conditions. Four fundamental stability models are analysed, both ideal (perfect) and with geometric imperfection. Besides geometrically exact theory, initial post-buckling behaviour and linearization are briefly sketched. This paper is concluded with comments about the influence of plasticity.
\end{abstract}

\title{
Keywords
}

structural stability, buckling, bifurcation point, limit point, imperfection

\section{Introduction}

With strong development of civil engineering, structures are becoming taller, longer, lighter and more slender. Almost every day, engineers reach new spans or height records, with the organization of the building site and short terms of construction that are just stunning. Because of large structural slenderness, stability problems become very important and often relevant for design. Therefore, knowledge of the structural stability theory is crucial for understanding and critical usage of modern norms and regulations. Furthermore, it is essential for the good design of new, and proper strengthening of existing buildings. In Figure 1, two examples of structural stability problems are given. In the first example, possible buckling of a large dome (see Figure 1a), including a reinforced concrete shell with large openings (see Figure 1b), and a reticulated part made of steel (see Figure 1c) can be seen. In the second example, we enclose the stability loss of a large steel tube compression zone in bending, with very fine local finite element mesh, used to capture short waves of the fundamental buckling mode (see Figures 1d-f). Efficiency of any structural system depends on shapes and sizes of structural elements and the behaviour of materials used. Between many possibilities, architects and engineers choose the appropriate elements and materials to maintain the designed shape for all loading combinations during planned structural life, such that

Corresponding author: Antonia Jaguljnjak Lazarević

antonia.jaguljnjak-lazarevic@oblak.rgn.hr safety and usage are never in question. If a structural system resists loads developing compressive forces, stiffness (especially in bending), is always reduced. If this reduction is large, we are faced with a loss of structural stability. In fact, this is a loss of the equilibrium position, usually followed by large displacements (primarily) and plastic deformations (secondarily). During, or at the end of this process, partial or complete structural failure is quite common. Today, we have good codes (Galambos and Surovek, 2008) and computational strategies (Wriggers, 2008) to avoid such a scenario. However, we should be very careful. Stability problems are (sometimes extremely) nonlinear and it is not often easy to handle calculations and obtain the correct solution. Moreover, because we cannot guarantee a unique solution, it is more difficult to solve a nonlinear model than a linear one. Therefore, such problems are often reserved for specialists in the area of computational structural stability. Briefly, they use carefully selected step-by-step procedures to obtain equilibrium curves and traverse critical (bifurcation and limit) points (Crisfield, Vol. 1, 2001). Sometimes, during calculations, very difficult phenomena arise, such as snap-through and snap-back. To pass these regions of the curve, basic nonlinear procedures are usually extended with additional strategies, like line-search and arc-length (Crisfield, Vol. 2, 2001). In spite of great success, black-box usage of nonlinear software is not always possible. Specialists must know the core of algorithms used and often manually give promising direction during calculations to prevent diverging of the numerical 


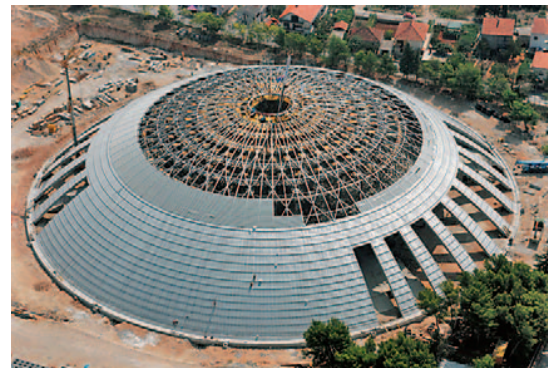

a)

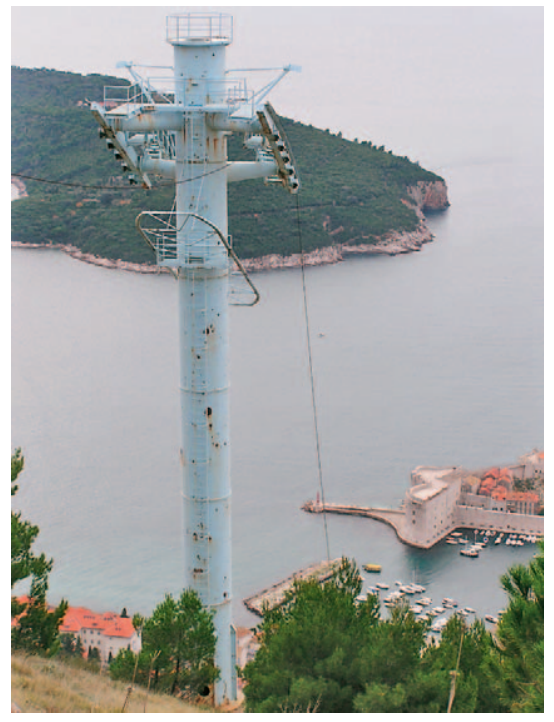

d)

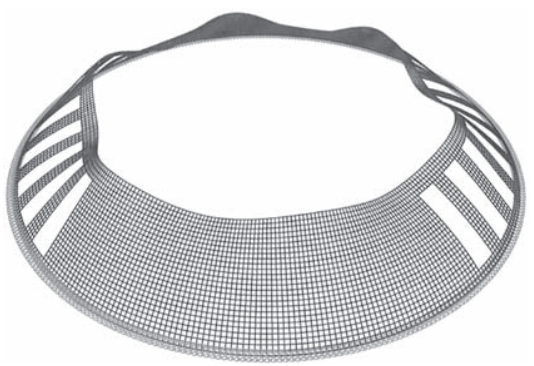

b)

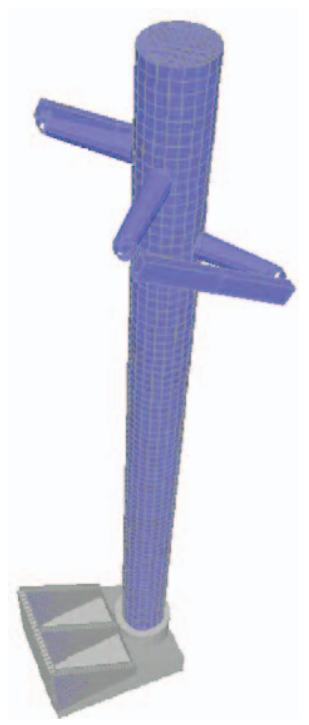

e)

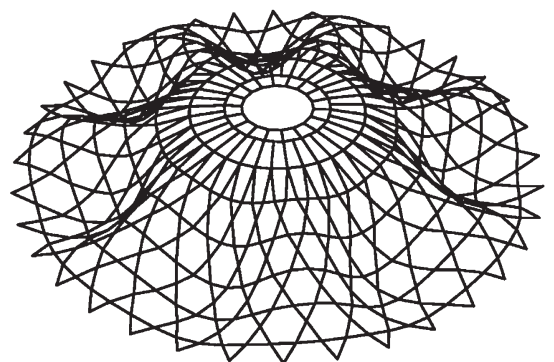

c)

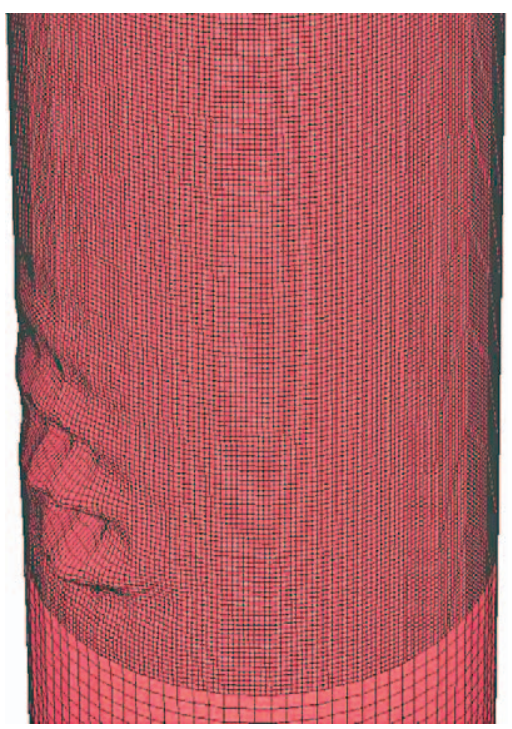

f)

Figure 1: Two practical civil engineering problems of stability

(Lazarević at al., 2010; URL: http://www.grad.unizg.hr/_download/repository/ts.pdf)

process. In the theory of computation, this scenario is often called man (human)-in-the-loop.

\section{Sources of nonlinearity}

Four groups of equations usually describe the classical linear boundary value problem of elasticity: equilibrium equations, strain or geometry relations, constitutive model and (force and displacement) boundary conditions. All groups are potential sources of nonlinearity. We will not develop equations in detail, but will rather use the appropriate examples to describe the effect of nonlinear behaviour, if separately induced in every group of equations. Here, we must emphasize, all equations are nonlinear in nature, but in the case of weak nonlinearity they can be linearized. In addition, this is a subject of engineering judgement, not computation.

\subsection{Nonlinearity of equilibrium equations}

Let us consider a simply supported frame loaded by two vertical forces $V$ and one horizontal force $H$. The height and span of the frame are $h$ and $L$. Loads are placed at the joints of the frame (see Figure 2a). Cross sections of the beam and columns are of a constant rec- tangular shape. In the linear case, the vertical reactions are $V \pm H h / 2$ and thehorizontal reactions are $H / 2$. The moment diagram is linear, with maximum values of $H h / 2$ at the joints of the frame beam (see Figure 2b). In the nonlinear case, global horizontal displacement of the frame $\Delta$ and local column deviation $\delta$ are large enough to amplify linear moments (see Figure 2c). Maximum joint values are now $H_{D} h+V_{D} \Delta$ and the local extreme along the columns is $V_{D} \delta$ (see Figure 2d). The forces $H_{D}, V_{D}$ and $H_{L}, V_{L}$ are right and left nonlinear horizontal and vertical reactions respectively. Note, unlike the linear case, horizontal reactions are no longer equal. The additional effect is nonlinear moment distribution along the frame. During beam and column design, all phenomena must be taken into account. In the case of significant differences between deflections and moments (say 30\% or more), the frame is usually stiffened by braces and walls to reduce lateral displacement. This efficient engineering approach is often used for any laterally flexible frame structure (such as in a slender high-rise building).

\subsection{Nonlinearity of strain (geometry) relations}

If an arbitrary rigid body is rotated by a large angle, say $\pi / 2$, small deformations of linear strain tensor cannot 


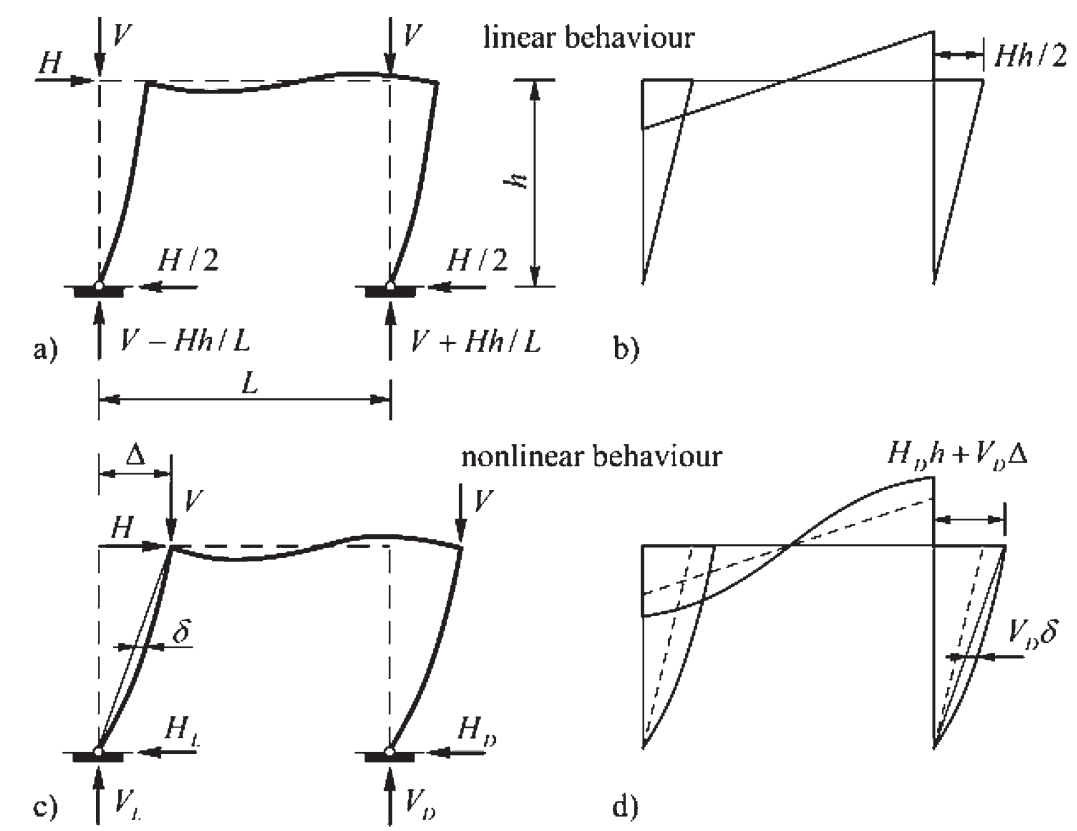

Figure 2: Effect of nonlinearity in equilibrium equations (Trahair, 1993)

represent the strain condition of the body. If the body point $A(X, Y)$ is marked, coordinates of the new position are $x=-Y$ and $y=X$ (see Figure 3a). Because this rotation is rigid, all deformation components must be zero. But that

$$
\begin{gathered}
\varepsilon_{x x}=\frac{\partial u_{x}}{\partial x}=\frac{\partial}{\partial x}(-X-Y)=-1 \\
\varepsilon_{y y}=\frac{\partial u_{y}}{\partial y}=\frac{\partial}{\partial y}(X-Y)=-1 \\
\varepsilon_{x y}=\frac{1}{2}\left(\frac{\partial u_{x}}{\partial y}+\frac{\partial u_{y}}{\partial x}\right)=\frac{1}{2}(-1+1)=0
\end{gathered}
$$

clearly means that longitudinal deformations (2) do not correctly respond. We usually solve this conflict using another measure of deformation. For example, in the case of the Green strain tensor, the new longitudinal strain measure is defined as:

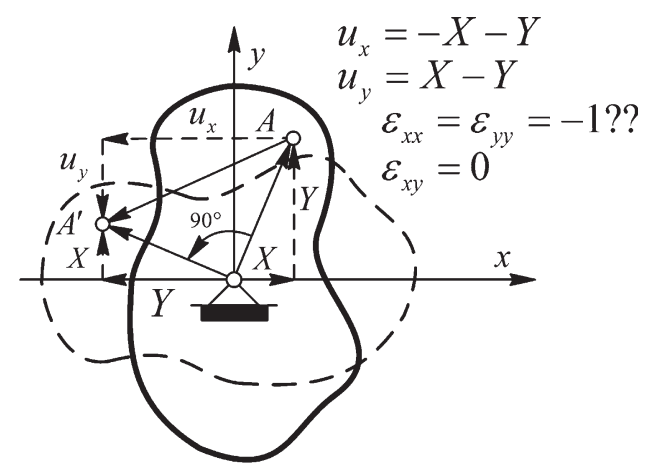

a)

$$
\varepsilon_{x x}=\frac{d s^{2}-d X^{2}}{2 d X^{2}}=\frac{\partial u_{x}}{\partial X}+\frac{1}{2}\left[\left(\frac{\partial u_{x}}{\partial X}\right)^{2}+\left(\frac{\partial u_{y}}{\partial X}\right)^{2}\right]
$$

where (see Figure 3b):

$$
d s^{2}=\left(d X+\frac{\partial u_{x}}{\partial X} d X\right)^{2}+\left(\frac{\partial u_{y}}{\partial X} d X\right)^{2}
$$

If deformations are small, the quadratic terms in equation (4) can be dropped, $X$ becomes $x$, and we recover equation (1). Now, it is easy to see that

$$
E_{x x}=-1+\frac{1}{2}\left[(-1)^{2}+(1)^{2}\right]=0
$$

It is not difficult to obtain expressions for the remaining deformations $E_{y y}$ and $E_{z z}$ (Bonet and Wood, 2008), and to show that in our case $E_{y y}=0$ and $E_{y z}=0$, which is the correct behaviour of planar rigid body rotation. By the way, treatment of large rotations is still one of the

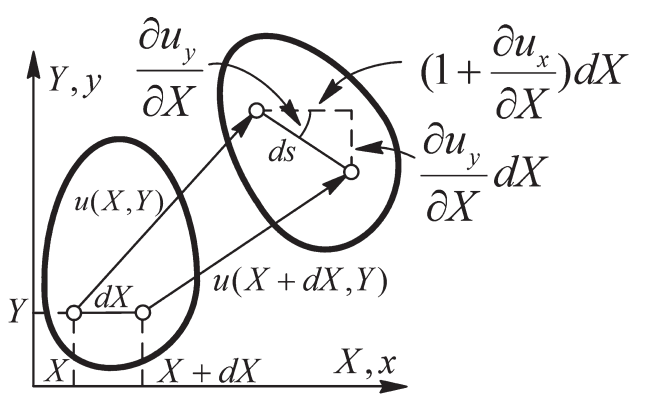

b)

Figure 3: Planar example of a rigid large rotation problem (Bonet and Wood, 2oo8) 
major challenges in nonlinear computational mechanics (Belytschko at al., 2009).

The equations of geometry are closely related to the so-called conditions of compatibility. They describe relations between strain components during deformation of the body. Simply stated, during the deformation process continuum must remain continuum. If such a condi-

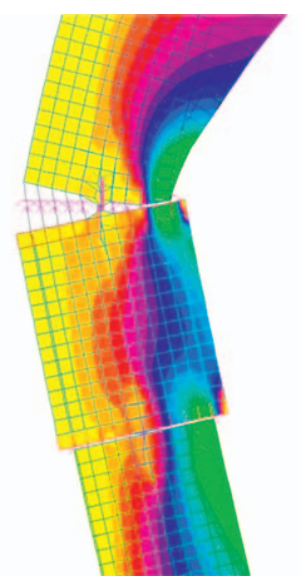

Figure 4: Separation and penetration of elements during the deformation process (Lazarević at al., 2010; URL: http://www.grad.unizg.hr/_download/repository/ts.pdf) tion is violated, as is in the case of penetrations, gaps or openings between structural elements (see Figure 4), tensile (or compressive) forces between them must be excluded. This problem is nonlinear in nature, as exclusion immediately means an equilibrium unbalance, which must be corrected by some iterative process.

\subsection{Nonlinearity of a constitutive model (hypothesis)}

Linear constitutive models are based on the linear dependence between stresses and corresponding strains (the famous Hooke law). If larger stresses are expected, nonlinear elasticity or plasticity effects must often be taken into account. There are many stress-strain relations (curves), used to model various material nonlinearities. Curves are usually based on standardized experiments. One of them is a simple tensile steel test. Figure 5 shows the result of such an experiment, that forms the basis for a commonly used elastic-perfectly plastic material model. Civil engineering structures are sometimes (even cyclically) stressed beyond their limit point and such strategies are commonly used to capture this behaviour. Notice in the figure, plasticity effects occur much earlier than the large strain effects described in the previous paragraph.

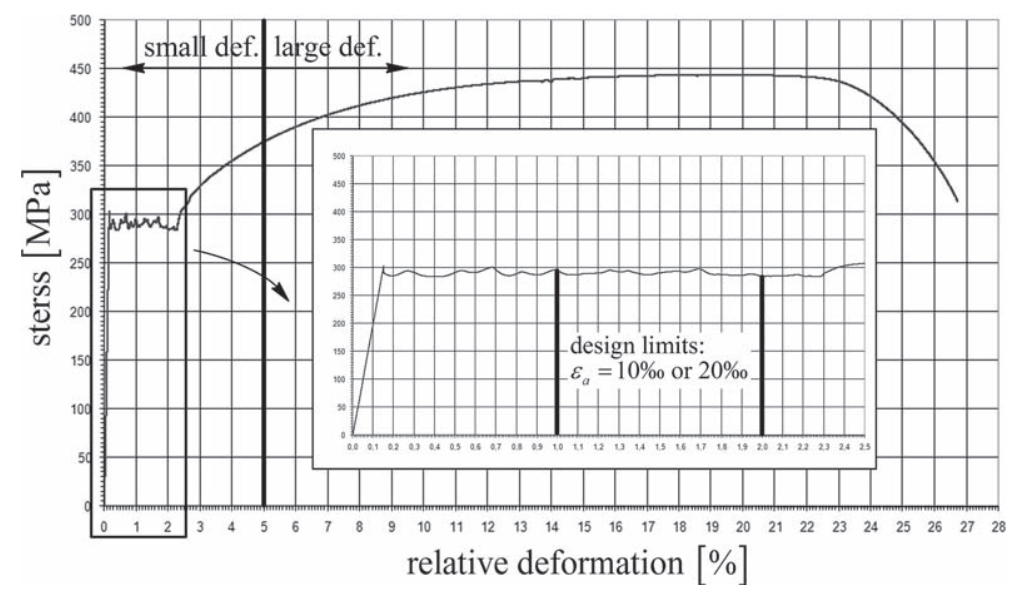

Figure 5: Result of a simple tensile steel test (Lazarević at al., 2010;

URL: http://www.grad.unizg.hr/_download/repository/ts.pdf)

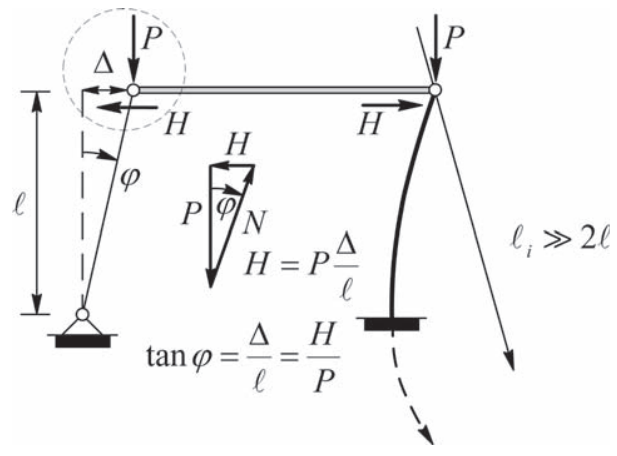

Figure 6: Sway buckling mode with a large buckling length (Bažant and Cedolin, 2003)

\subsection{Nonlinearity in force boundary conditions}

If a frame load is sufficiently large and lateral stiffness is small enough, a very interesting buckling mode with change in load direction arises. This phenomenon is known as the follower force and simply shows that a sway frame column may have a buckling length larger than $2 l$ (see Figure 6). Notice that two equal and opposite horizontal forces $H$ must appear, to maintain equilibrium of the left joint and the whole frame. These components make joint resultants (with the force $P$ ) inclined, which is the reason for the large buckling length of the right column. 

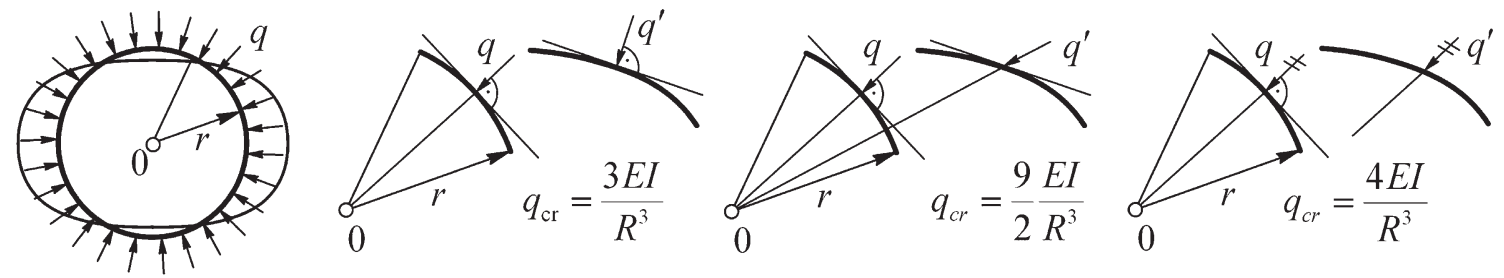

Figure 7: Various stability problems of planar circular ring (Alfutov, 20oo)

Another interesting problem of this category is the stability of the planar circular ring. Various assumptions about load positions after bucking give different critical pressures $q_{c r}$ (see Figure 7). See from the picture, it is not irrelevant whether the load is always perpendicular to the tangent of the ring, passes through the ring origin, or stays parallel with the initial position.

\subsection{Nonlinearity due to displacement boundary conditions}

Another source of nonlinear behaviour is related to boundary constraints, which changes with the deformations of the system. An example is possible contact between two horizontal bars of lengths $l_{1}$ and $l_{2}$ (see Figure 8). Only the left bar is loaded by the longitudinal force . Bars are initially separated and behave as individual elements until contact is reached. This happens when a loaded bar is stretched enough to touch the right bar. In other words, displacement $u_{1}$ and elongation $\Delta$ are so large to make contact. After that, the right bar is pressed, displacement $u_{2}$ is not zero and the system become stiffer. This obvious change of the static system (two cantilevers transform into one clamped bar), is a source of nonlinear behaviour.

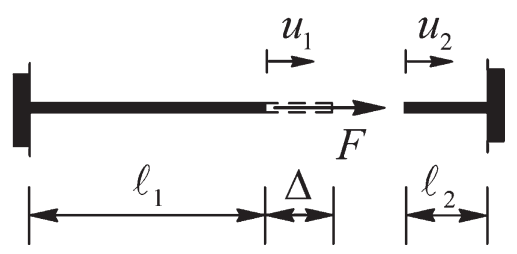

Figure 8: Simple two bar problem (Wriggers, 2008)

a)

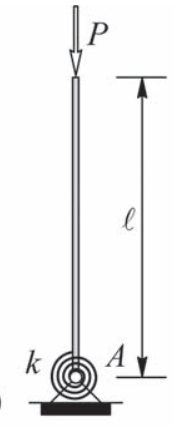

b)

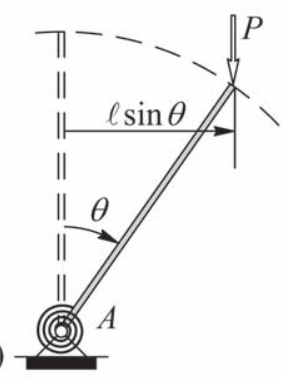

c)

\section{Four fundamental cases}

Despite the fact that there are numerous elastic stability problems, thanks to the work of W.T. Koiter (Hjelmstad, 2005 and van der Heijden, 2009), it is possible to distinguish four fundamental cases: stable and unstable symmetric bifurcation, asymmetric bifurcation and limit point behaviour. This classification is important because it classifies not only ideal, but also imperfect elastic systems. Let us briefly describe each case, using simple models with one rotational degree of freedom $\theta$ (Hjelmstad, 2005). The solutions presented are geometrically exact, because assumptions such as $\sin \theta \approx \theta$ or $\cos \theta \approx 1$ are not used. The first model is described in detail and others are only briefly sketched.

\subsection{Stable symmetric bifurcation}

Consider a straight rigid column (cantilever) of height $l$, elastically restrained by a linear rotational spring of stiffness $k$ (see Figure 9a). The column is loaded by a vertical force $P$ at the top. In the straight position $\theta=0$ spring is unstressed. This undeformed position is obviously possible, because it satisfies the vertical equilibrium of the model. However, the balance at a certain angle also exists (see Figure 9b). From the moment equilibrium of the inclined (deformed) position about point $A$, we get $P l \sin \theta=k \theta$ and $P=k / l(\theta / \sin \theta)$. Of course, force $P$ always remains straight.

Vertical and curved thick lines on Figure 9c are the equilibrium functions described. Notice two important properties of the solution. First, one of the functions is nonlinear and the principle of superposition is not valid any more. Second, the solution is not unique, because

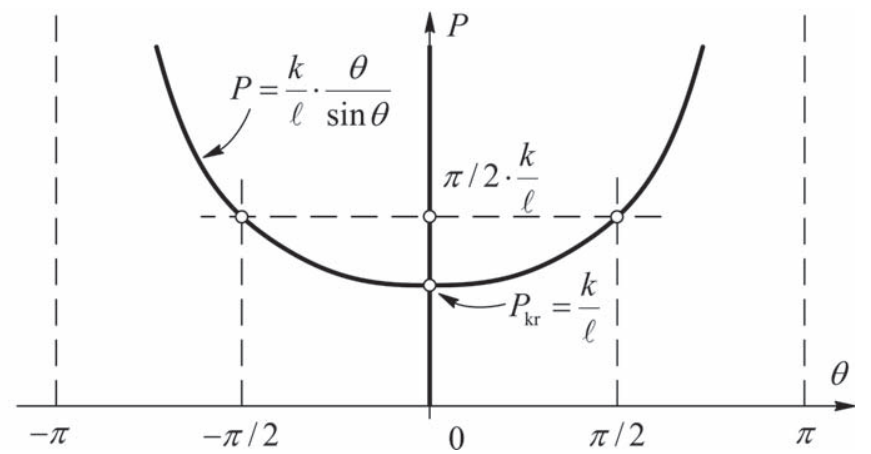

Figure 9: Stable symmetric bifurcation: a) model, b) deformed position, c) equilibrium curves

(Hjelmstad, 2005) 
two equilibrium functions exist. Furthermore, three angles, 0 and $\pm \pi / 2$ correspond to one force level, say $P=$ $\pi / 2(k / l)$. In addition, there is special point called the bifurcation point. It is an intersection of equilibrium functions. The corresponding load level is known as critical force $P_{k r}=k / l$. It is not possible, without the theorem of minimum potential energy, to decide about the character of equilibrium positions, whether they are stable or unstable (Simitses and Hodges, 2006). For this example, it is easy to prove that the straight position is stable before and unstable after the bifurcation point. Physically, stability (instability) means resistance (non-resistance) to a load increase. Inclined positions, characterized by the left and right equilibrium branch that emanate from the bifurcation point, are always stable. Exactly at the bifurcation point, equilibrium is also stable (Čengija, 2016). With these features, we talk about the bifurcation or branching point of the first kind. The region before bifurcation is called pre-critical and after that post-critical. The loading and unloading direction always lies on the same stable curve, without executing jumps. Also, no- tice the horizontal tangent at the critical point and symmetry with respect to the loading axis, of both, curve and post-critical (stable) behaviour. Therefore, this phenomenon is known as the stable symmetric bifurcation. It is easy to see that curves are theoretically equal, with the same probability of realisation. In reality, even small imperfections decide which branch will be favoured. Similar behaviour exists in axially loaded slender beams and thin plates, both without imperfections.

\subsection{Unstable symmetric bifurcation}

The second example consists of a rigid vertical bar, hinged at the bottom and elastically restrained at the top $B$ by a horizontal spring of stiffness $k$. The model is loaded by a vertical force $P$ which always remains straight (see Figure 10a). Four equilibrium positions are now possible: three vertical and one inclined (see Figure 10b). The moment equation about point $A$ is $P l \sin \theta=k l \sin \theta l \cos \theta$. This equation is easily rearranged to obtain $(P-k l \cos \theta) \sin \theta=0$. So, the possi-

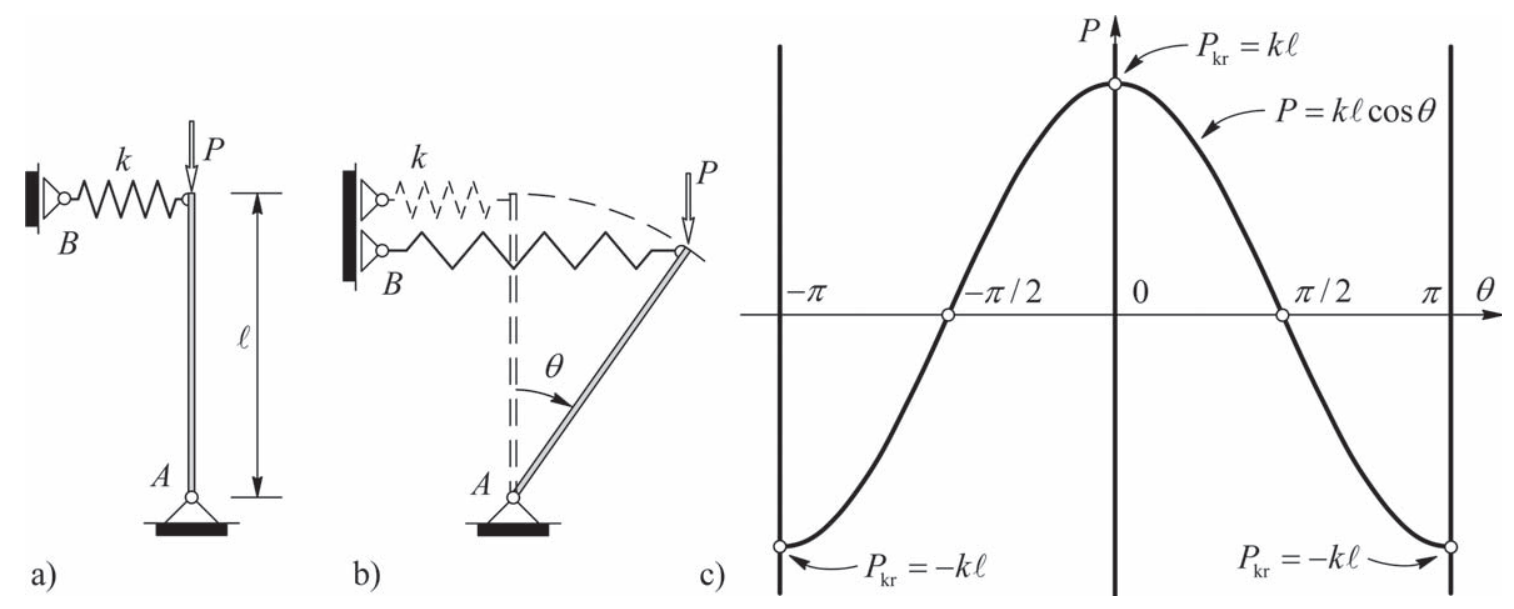

Figure 1o: Unstable symmetric bifurcation: a) model, b) deformed position, c) equilibrium curves (Hjelmstad, 2005)

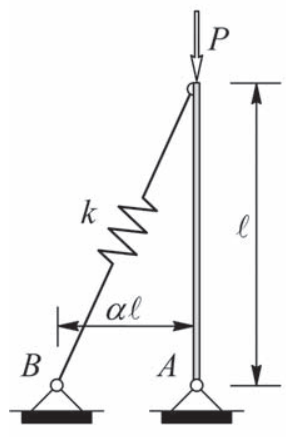

a)

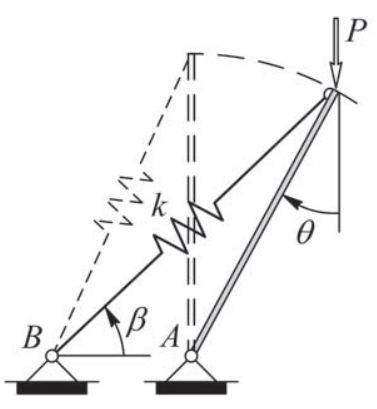

b)

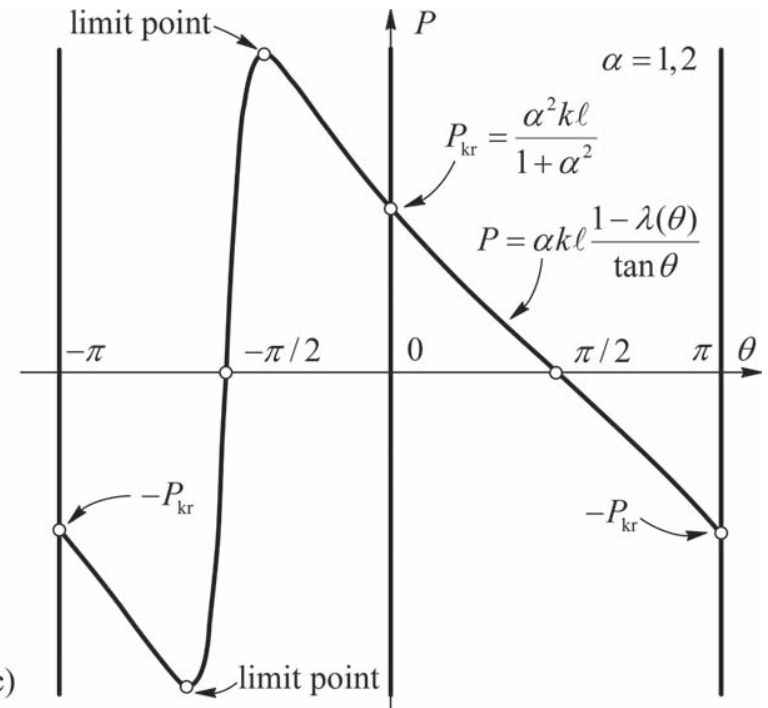

Figure 11: Asymmetric bifurcation: a) model, b) deformed position, c) equilibrium curves (Hjelmstad, 2005) 
bilities are $\sin \theta=0$ or $P-k l \cos \theta=0$. The solutions of the first equation are 0 and $\pm \pi$ and of the second equation $P=k l \cos \theta$. All functions are drawn on Figure 10c. The critical force at the bifurcation point of practical importance is $k l$. As in the previous example, the initial position is stable before and unstable after the bifurcation point, but contrary to the first model, the inclined position is always unstable. In such conditions, the branching point is called the bifurcation point of the second kind. At that point, the tangent on the equilibrium curve is also horizontal. But, after the point is reached, the system suddenly jumps to a reversed stable vertical position given by $\pi$ or $-\pi$. As in the previous case, because of the solution symmetry (in the shape and character of stability), small real imperfections govern the direction of the motion. Because post-critical behaviour is unstable, this problem is known as the unstable symmetric bifurcation. This is the behaviour of deep arches, cylindrical panels and stiffened plates, not influenced by imperfections.

\subsection{Asymmetric bifurcation}

This phenomenon can also be described by a rigid vertical bar hinged at point $A$, but now additionally restrained by an inclined spring from point $B$ to the top of the bar. Spring stiffness is $k$ again. As usual, the vertical force $P$ is acting at the top of the column (see Figure 11a). Vertical equilibrium positions are 0 and $\pm \pi$ again, while the inclined position (see Figure 11b) is characterized by $\alpha k l[1-\lambda(\theta)] / \tan \theta$ (see Figure 11c), where $\alpha$ is a fraction of the bar length and $\lambda(\theta)=L(0) / L(\theta)$ is a ratio of the undeformed to the deformed length of the spring. Critical force is $\alpha^{2} k l /\left(1+\alpha^{2}\right)$ and the corresponding tangent is not horizontal. The right side of the equilibrium curve is unstable and the left one is stable. Obviously, the response of this example is not symmetric. Therefore, this problem is known as the asymmetric bifurcation. The corresponding branching point is called the bifurcation point of the third kind. After reaching that point, the system executes a sudden jump to the reversed vertical position on the right, given by $\theta=\pi$. The system can be deformed to the left, only if the right side is properly restrained. This type of behaviour is typical for frames and cylindrical or spherical shells without imperfections. At the end, notice the maximum of the equilibrium function on the left side of Figure 11c. It is called the limit point and it is important for the example that follows.

\subsection{Limit point behaviour}

This example is different from the three previous cases. It is well described by a simple, elastically supported truss (see Figure 12a). Bars are inclined and rigid. The left bar is hinged at the bottom and the right is vertically fixed and horizontally restrained by the linear spring of stiffness $k$. The truss is loaded by a vertical force $P$ at the top. In the initial position, the spring is unstressed. From the moment equation about point $A$, we get $P=4 k l[1-\cos \alpha / \cos \theta]$. This is the only equilibrium curve, as $u=0$ (vertical axis) is not in the equilibrium position anymore (see Figure 12b). The curve is plotted using the additional relations $\sin \theta=(h-u) / l$, $\cos \alpha=a / l$ and $\cos \theta=\left[1-((h-u) / l)^{2}\right]^{1 / 2}$, which are obvious from the figure. Since only one equilibrium function exists, the branching (bifurcation) point never appears. Stability is lost at the so-called limit point and the pre-critical part of the curve is not straight. In the theory of stability, this phenomenon is known as the snap through. Such behaviour is characteristic of shallow arches and shells. At the end of this section, let us mention that bifurcation and limit points have a unique name - critical points. After reaching that point, the initial position of any model is no longer stable.

\section{Initial post-buckling behaviour}

It is possible to simplify equilibrium equations using the Taylor series expansion in the vicinity of $\theta=0$. The main idea is to use the truncated series of trigonometric functions. Applying only the first two coefficients of the series, equilibrium equations of the preceding examples

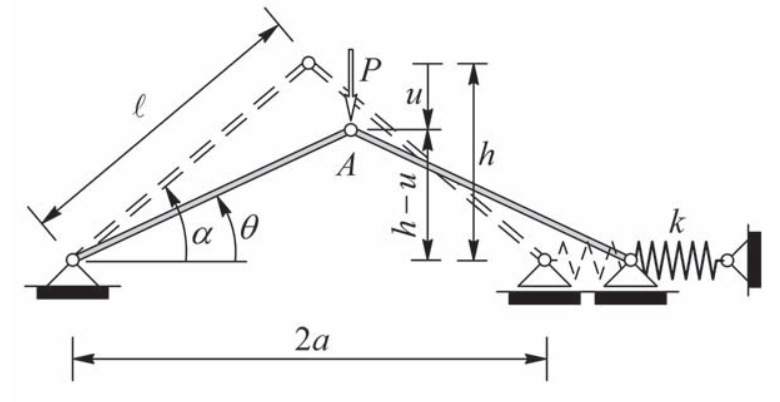

a)

Figure 12: Limit point behaviour: a) model and deformed position, b) equilibrium curve (Lazarević at al., 2010; URL: http://www.grad.unizg.hr/_download/repository/ts.pdf) 
are: $P=k / l\left(1+\theta^{2} / 6\right)$, for stable symmetric bifurcation, $P=k l\left(1-\theta^{2} / 2\right)$, for unstable symmetric bifurcation, $P=\alpha \gamma k l(1-3 / 2 \gamma \theta)$, for asymmetric bifurcation and $P=2 k l\left(\alpha^{2}-\theta^{2}\right) \theta$, for limit point behaviour. For simplification purposes, in the third equation we use the constant $\gamma=\alpha /\left(1+\alpha^{2}\right)$, while in the last equation relations $\alpha=h / l$ and $\theta=(h-u) / l$ are used for plotting $P$ versus $u$ (not $\theta$ ). Approximate solutions (together with exact curves from the previous section) are sketched in Figure 13. This approach is known as second order theory, as (at most) quadratic function is enough to approximate equilibrium in close vicinity of the initial position. In the third example, even linear function is a satisfactory solution (see Figure 13c). (That's why we used the phrase "at most".) Also, a relatively crude approximation in the fourth example is the consequence of a large angle $\alpha$ (deep truss, $\alpha=\pi / 4$ ). In the case of a shallow truss, matching would be much better. Because, it is possible to obtain the equilibrium equation as the first derivative of the energy functional, and the character of that equilibrium examined by the second derivative, obviously, for the quadratic equilibrium function to exist, energy must be of the fourth order (Godoy, 2000). Therefore, for initial post-buckling behaviour, it is sufficient to approximate energy by:

$$
\begin{gathered}
\Pi(\theta)=a_{0}+a_{1} \theta+a_{2} \theta^{2}+a_{3} \theta^{3}+a_{4} \theta^{4}- \\
-P\left(b_{0}+b_{1} \theta+b_{2} \theta^{2}+b_{3} \theta^{3}+b_{4} \theta^{4}\right)
\end{gathered}
$$

From this equation, some general conclusions can be made. Constants $a_{0}$ and $b_{0}$ have no influence on the solution, as they vanish by the first derivative. If $a_{1} \neq 0$ and tions. Finally, some computer codes from the seventies (still in use), are based on series expansions, not on true solutions. For deeper understanding of such software, knowledge about this strategy is very useful.

\section{Linearization: Euler critical force}

Sometimes, it is very difficult (even numerically) to obtain the equilibrium function of some complicated model. It is easier to find the critical point $\left(\theta_{k r}, P_{k r}\right)$ only. Furthermore, this point is the basis for many design formulas of national standards. The idea is to use the most linear coefficient in the Taylor series expansion, but equilibrium is still set on the deformed model. Now, the approximation is valid only for a "very small" $\theta$ (not just "small" as in the previous section), and we are talking about linearization in the theory of elastic stability. Associated energy is a quadratic function of $\theta$ and it is possible to access the undeformed (straight) position only. Additionally, we can find the bifurcation point and initial form of the instability-buckling shape. The associated critical force is known as the Euler critical force, according to the contribution of the great mathematician L. Euler. Furthermore, we know that before the critical point, the undeformed configuration is stable and after that point, it is unstable. The behaviour exactly at the bifurcation point and of the deformed configuration after that point is not known anymore. This is because of a very crude approximation strategy. Because of that, we are talking about indifferent equilibrium conditions at and after the critical point. The equilibrium function that emanates from the bifurcation point is a simple horizon-

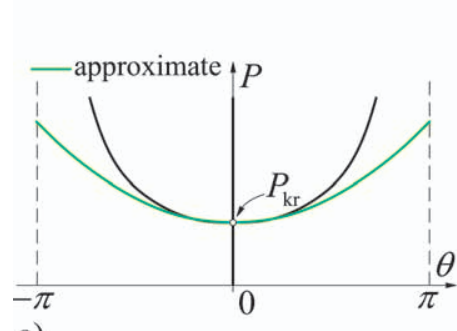

a)

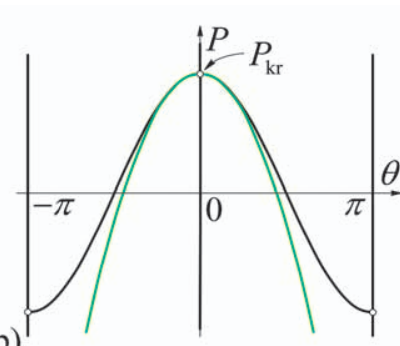

b)

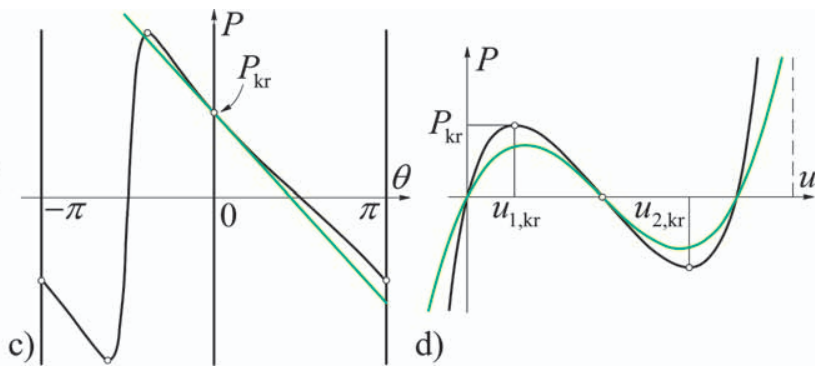

c)

d)

Figure 13: Exact and approximate equilibrium curves of four fundamental cases (Lazarević at al., 2010; URL: http://www.grad.unizg.hr/_download/repository/ts.pdf)

$b_{1} \neq 0$ the vertical axis is not the equilibrium axis anymore. The linear stiffness $k$ depends on $a_{2}>0$. The remaining coefficients govern post-critical behaviour of the model. Thus, if $a_{3}=0$, bifurcation is symmetric (stable or unstable, there is no decision yet), and for $a_{3} \neq 0$ it is asymmetric. Finally, if $\left(a_{4}+b_{4}\right)>0$ bifurcation is stable and for $\left(a_{4}+b_{4}\right)<0$ it is unstable. This famous Koiter classification is relatively general and is crucial for understanding, not only ideal, but also imperfect systems. Moreover, thanks to this approach, it is easy to distinguish the influence of every coefficient on the stability. Such conclusions are not possible from the exact solu-

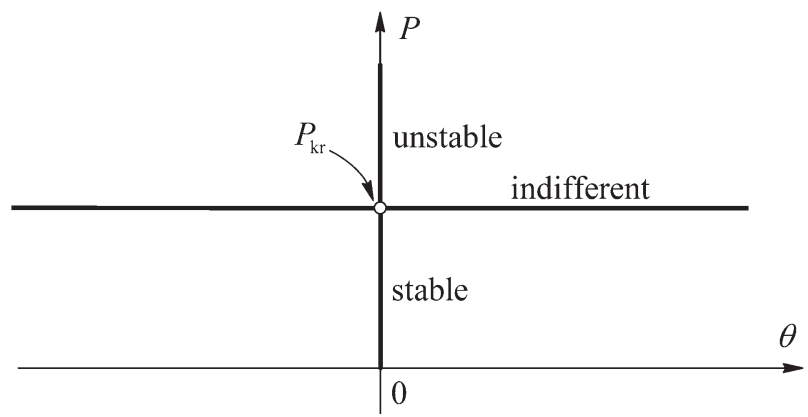

Figure 14: Equilibrium curve after linearization 
tal line and it is the same for the first three examples of the previous section (see Figure 14). Obviously, all the post-critical information is completely lost. In the fourth example, the limit point behaviour cannot be approximated using linear assumption, because the pre-critical part of the equilibrium curve is not linear. Eventually, the critical force can be reached through a series of successive linear approximations that imitates a nonlinear approach (Bathe, 1996).

\section{The effect of imperfections}

In the real (not only) civil engineering world, imperfections always exist. We can divide them into geometric, material and numerical. The first group includes various disturbances of structural shape, loads and boundary conditions. The second group consists of inhomogeneous material properties, effects of plasticity and residual stresses. The third group usually includes rounding off errors and controlled perturbations. The main problem is that imperfections are not known in advance. We can easily prescribe the amount of imperfection on the safe side, but a good imperfection shape, especially of complex structures, is very difficult to propose. In this paper, only geometric imperfection is treated. In the first three examples, it is simply imposed by the initial angle $\theta_{0}$ and in the last example by vertical displacement $u_{0}$, both measured from the undeformed position. The effect of imperfections is given in Figure 15.
In Figures 15.a to $\mathbf{c}$, we can see that the vertical position is not the equilibrium position anymore and that the bifurcation points disappear. If we examine the so-called imperfection sensitivity functions $P_{k r}=f\left(\theta_{0}\right)$, sketched for all figures on the right), the first function rises, so geometric imperfection does not deteriorate the Euler critical force. Furthermore, equilibrium functions from the right side have no critical point at all. Therefore, this is no longer a stability but a large displacement problem. In the remaining examples, functions have descending branches preceded by limit points, placed lower than the critical points of the perfect system. This means that the Euler force is reduced. As it can be seen from the formulas, for the second and third example reductions are governed by exponents $2 / 3$ and $1 / 2$, so we usually talk about two-third and one-half power low sensitivity functions. Both functions have a vertical tangent at $\theta_{0}=0$, but the second curve is steeper, which is associated with a higher imperfection sensitivity. The fourth example is of moderate sensitivity, because the sensitivity function is almost linear (see Figure 15.d). Notice, as $\theta_{0} \rightarrow 0$ all equilibrium functions get closer to that without imperfections. For the first and third example, equilibrium functions from the right side and corresponding parts of the sensitivity curves are more realistic. Curves on the left can be reached, but an additional horizontal force (for the first example) or a horizontal support (for the third example), should be imposed. The fourth example is interesting, as for some imperfections $\left(u_{0}<0\right.$, that

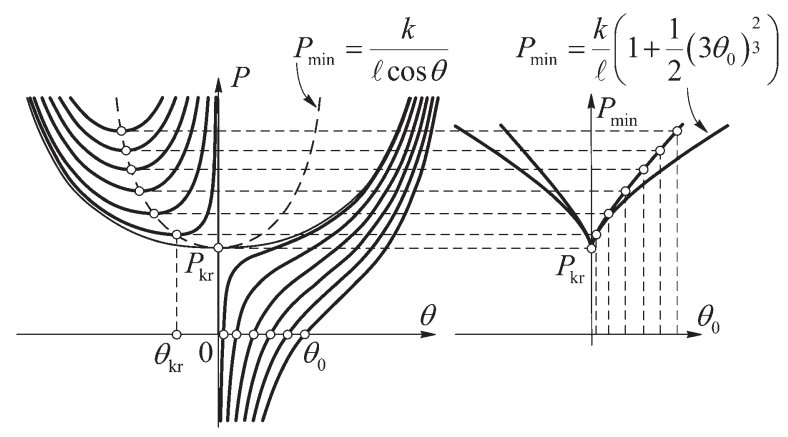

a)
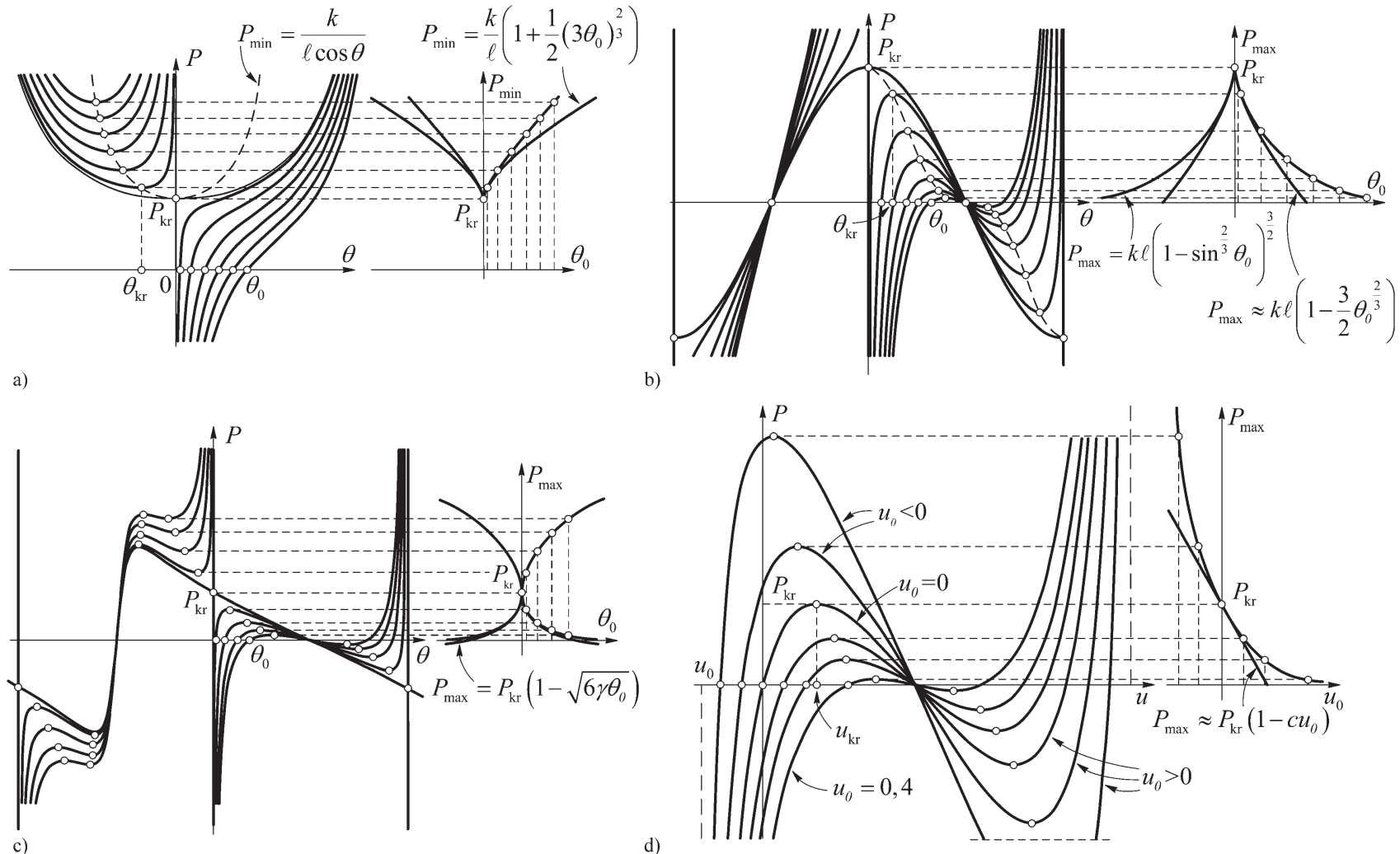

Figure 15: Imperfections: equilibrium curves and sensitivity functions for all four models (Lazarević at al., 2010; URL: http://www.grad.unizg.hr/_download/repository/ts.pdf) 


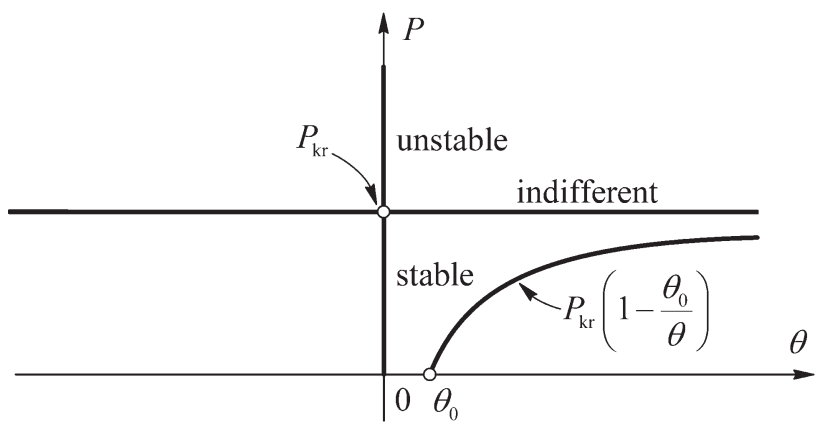

Figure 16: Linearization and geometric imperfection

makes a truss higher), the critical force rises. At the end, it is possible to use imperfection even in the linear theory of stability. This approximation is known as $P-\Delta$ effect and the equilibrium function for the first three examples is always the same: $P=P_{k r}\left(1-\theta_{0} / \theta\right)$. (We said that for the fourth example linearization is not well functioning.) As the load increases, the equilibrium function asymptotically approaches the Euler critical force (see Figure 16.). This model is found to be very useful in engineering codes of practice.

\section{Conclusions}

We can conclude this brief overview of the basic stability phenomena with a few words on the influence of plasticity. Obviously, if a structural element (a column for example), is not too slender (which is not uncommon), it may remain straight after a proportional (or a very close yield) limit is reached. Therefore, the plasticity effect takes action before losing stability and the linear stiffness $k$ is not valid any more. Here, we are talking about the nonlinearity of the stress-strain diagram, mentioned in Section 2.3. In engineering words, we must replace the linear (Young) modulus $E=$ const. with the (usually smaller) tangent modulus $E_{t}=d \sigma / d \varepsilon$ of material used. The tangent modulus depends on the deformation (stress) level and the material model adopted, which in the case of overall nonlinearity makes calculations (and computations) more complex. Generally, with the additional presence of imperfections, the bifurcation point turns to the limit point and post-critical behaviour usually becomes unstable. Without imperfections, stability loss remains in the form of bifurcation, but with the ascending (not horizontal) tangent on the equilibrium curve at the critical point. This is the celebrated conclusion of Shanley (maybe the most influential contribution after Euler), given at 1947, after almost fifty years of controversy in the field of plastic column buckling. During that period, many famous researchers blundered (Engesser twice), while trying to explain the discrepancy between the theory and carefully conducted experiments on real columns. In any case, these historically very interesting events and results, that undoubtedly have influenced the development of the modern theory of stability, should be the subject of a separate paper (Byskov, 2013).

\section{References}

Alfutov, N.A. (2000): Stability of ElasticStructures. Springer - Verlag, Berlin

Bathe, K.-J. (1996): Finite Element Procedure. Prentice - Hall, Inc., Upper Saddle River

Bažant, Z.P.; Cedolin, L. (2003): Stabilty of Structures. Elastic, Inelastic, Fracture and Damage Theories. Dover Publications, Inc., Mineola

Belytschko, T.; Liu, W.K.; Moran, B. (2009): Nonlinear Finite Elements for Continua and Structures. John Wiley \& Sons, Ltd., Chichester

Bonet, J.; Wood, R.D. (2008): Nonlinear Continuum Mechanics for Finite Element Analysis. Cambridge University Press, Cambridge

Byskov, E. (2013): Elementary Continuum Mechanics for Everyone. With Applications to Structural Mechanics. Springer Science + Business Media, Dordrecht

Crisfield, M.A. (2001): Non-linear Finite Element Analysis of Solids and Structures. Volume 1. John Wiley \& Sons, Ltd., Chichester

Crisfield, M.A. (2001): Non-linear Finite Element Analysis of Solids and Structures. Volume 2 Advanced Topics. John Wiley \& Sons, Ltd., Chichester

Čengija, A. (2016): Utjecaj imperfekcije na stabilnost jednostavnijh štapnih konstrukcija (Influence of imperfections on stability of simple bar structures). Završni rad, Rudarsko-geološko-naftni fakultet Sveučilišta u Zagrebu, Zagreb

Galambos, T.V. and Surovek, A.E. (2008): Structural Stability of Steel. John Wiley \& Sons, Inc., Hoboken

Godoy, L.A. (2000): Theory of Elastic Stability. Analysis and Sensitivity. Taylor and Francis, Philadelphia

Hjelmstad, K.D. (2005): Fundamental of Structural Mechanics. Springer Science + Business Media, Inc., New York

Lazarević, D.; Anđelić M.; Uroš, M. (2010): Oblikovanje i proračun kupole dvorane "Krešimir Ćosić» u Zadru (Design and structural analysis of Krešimir Ćosić dome in Zadar), Građevinar, 62, 10, 875-886. (in Croatian)

Simitses, G.J.; Hodges, D.H. (2006): Fundamentals of Structural Stability. Butterworth-Heinemann, Burlington

Trahair, N.S. (1993): Flexural-Torsional Buckling of Structures. CRC Press Inc., Boca Raton

URL: http://www.grad.unizg.hr/_download/repository/ts.pdf (accessed 2nd November 2016)

van der Heijden, A.M.A. (2009): W.T. Koiter's Elastic Stability of Solids and Structures. Cambridge University Press, Cambridge

Wriggers, P. (2008): Nonlinear Finite Element Methods. Springer - Verlag, Berlin 


\section{SAŽETAK}

\section{Osnovni modeli stabilnosti konstrukcija}

U radu su opisani osnovni modeli stabilnosti konstrukcija. Nakon nekih općih komentara o stabilnosti u području građevinarstva spomenuta su četiri temeljna izvora nelinearnosti: nelinearnost jednadžbi ravnoteže, geometrijskih odnosa, zakona ponašanja te rubnih uvjeta po silama i pomacima. Analizirana su četiri osnovna modela stabilnosti: idealni modeli i modeli s geometrijskom imperfekcijom. Osim geometrijski točne teorije dan je osvrt na početno poslijekritično ponašanje i linearizaciju. Rad završava komentarima o utjecaju plastičnoga popuštanja.

\section{Ključne riječi}

stabilnost konstrukcije, izbočenje, točka razgranjenja, granična točka, imperfekcija 